\title{
A IMPORTÂNCIA DA EDUCAÇÃO PARA FORMAÇÃO DE SOCIEDADES RESILIENTES
}

\section{The importance of education for the formation of resilient societies}

\author{
André Luiz da Silva Filho \\ Mestrando em Geografia pela Universidade do Estado do Rio de Janeiro \\ andrefilhogeo@gmail.com \\ Marina Aires \\ Doutoranda do Programa de Pós Graduação em Geografia pela UFF \\ marinageouff@gmail.com \\ Wilson Messias dos Santos Junior \\ Doutor em Geografia pela Universidade do Estado do Rio de Janeiro \\ wilson.messias@gmail.com
}

Artigo enviado para publicação em 24/05/2020 e aceito em 19/07/2020

DOI: $10.12957 /$ tamoios.2020.48606

\begin{abstract}
Resumo
Desastres de origens naturais são causados por fenômenos da natureza que atuam independentemente da ação humana e, atingem áreas ou regiões habitadas pelo homem, causandolhe danos. $\mathrm{O}$ atual modelo de desenvolvimento da sociedade, que ao longo dos últimos séculos, baseia-se em um planejamento urbano desordenado, que acarreta um processo de degradação ambiental, resultando em uma sociedade susceptível a eventos naturais extremos. A redução dos riscos para eventos extremos ainda não se encontra presente como parte do cotidiano da população, em especial a brasileira, desse modo surge a importância da mudança desse panorama através da educação. $\mathrm{O}$ artigo dedica-se ao estudo da educação resiliente no ensino básico como uma importante medida para a prevenção das consequências de desastres naturais. Utiliza-se como materiais e métodos pesquisa bibliográfica em entidades internacionais como Organização das Nações Unidas (ONU) e Fundo das Nações Unidas para a Infância (UNICEF), estudo sobre a base curricular do Estado do Rio de Janeiro e a atuação de órgãos públicos como a Defesa Civil do Município do Rio de Janeiro e o Centro Nacional de Monitoramento e Alertas de Desastres Naturais (CEMADEN).
\end{abstract}

Palavras-chave: Desastres; Educação Resiliente; Redução de riscos.

\begin{abstract}
Disasters of natural origin are caused by phenomena of nature that act independently of human action and reach areas or regions inhabited by man, causing damage to it. The current model of society development, which over the last centuries, is based on a disorderly urban planning, which leads to a process of environmental degradation, resulting in a society susceptible to extreme natural events. Risk reduction for extreme events is not yet present as part of the daily life of the population, especially in Brazil, so the importance of changing this scenario through education emerges. The article is dedicated to the study of resilient education in basic education as an important measure for the prevention of the consequences of natural disasters. Bibliographic research in international entities such as the United Nations (UN) and the United Nations Fund is used as materials and methods. United for Children (UNICEF), study on the curricular basis of the State of Rio de Janeiro and the performance of public bodies such as the Civil Defense of the Municipality of Rio de Janeiro and the National Center for Monitoring and Natural Disaster Alerts.
\end{abstract}

Keywords: Disasters; Resilient Education; Risk reduction. 


\title{
Introdução
}

Desastres de origens naturais são aqueles causados por fenômenos e desequilíbrios da natureza que atuam independentemente da ação humana e, são assim denominados quando atingem áreas ou regiões habitadas pelo homem, causando-lhe danos (AMARAL et al., 2009). Os registros de perdas econômicas, impactos sociais, de infraestrutura e ecológicos decorrentes de inundações e outras catástrofes climáticas em áreas urbanas ao longo das últimas décadas mostram uma tendência de aumento dos prejuízos associados a eles. O que o transforma em calamidade pública são as profundas alterações resultantes da urbanização, uma vez que ocorre a remoção de vegetação nativa, aumento de impermeabilização do terreno e ocupação de áreas ribeirinhas. Além disso, a ocupação histórica de áreas de risco, aliada à falta de um sistema de alerta de enchentes e de treinamento das populações para lidar com essas situações, oferece um ambiente propenso a tragédias (ROSMAN et. al., 2012). Além disso, Afonso (2015, p. 184) ressalta que no caso do Brasil:

\begin{abstract}
A maior parte das cidades brasileiras cresceu sem levar em conta ou minimizando a relevância das características e processos naturais dos sítios sobre os quais a população e as redes logísticas se instalavam. Apesar de algumas cidades brasileiras possuírem projetos de uso e ocupação que consideravam a periculosidade dos ambientes naturais, a aplicação da legislação nem sempre ocorreu, haja vista as dificuldades de controle e fiscalização. Assim, boa parte da população urbana brasileira é vulnerável a perigos relacionados a processos naturais, habitando zonas de risco (AFONSO, op.cit).
\end{abstract}

O objetivo deste artigo é demonstrar a importância da introdução da temática de prevenção das consequências dos eventos extremos na educação básica para a formação de uma sociedade consciente dos riscos e que seja capaz de compreender de como atuar diante de tais situações. Para isso realizou-se pesquisa bibliografia como modo compreender quais ações estão ocorrendo em outros países e no Brasil. O presente trabalho busca apresentar projetos desenvolvidos pelo Centro Nacional de Monitoramento e Alerta de Desastres Naturais (CEMADEN) e pela Defesa Civil do município do Rio de Janeiro.

A educação habilita os indivíduos e as comunidades a compreenderem-se e entenderem suas ligações com um meio ambiente social e natural de modo mais amplo. Esta compreensão constitui a base duradoura sobre a qual está alicerçado o respeito ao mundo que nos rodeia e aos homens que o habitam (UNESCO, 2005).

É comum focalizar o sistema educacional formal como lugar de aprendizagem. Entretanto, aprende-se tanto dentro quanto fora do sistema escolar, nas interações da vida cotidiana, na família, no trabalho, frente ao computador ou televisão, observando, copiando, experimentando, refletindo, articulando, ouvindo e aprendendo com os erros. As práticas e comportamentos serão internalizados no comportamento individual e coletivo por meio de múltiplas decisões e ações diárias (UNESCO, op.cit).

Em caso de desastre naturais, as crianças são as mais afetadas, já que a interrupção no sistema de ensino afeta um direito fundamental das crianças, o direito à educação. Ganhos de desenvolvimento em educação se contrapõem a danos ou destruição de ambientes escolares, à interrupção prolongada da educação, ao acesso limitado à educação e à queda na qualidade do ensino (UN, 2015).

Só em 2011, 302 riscos resultaram em desastres que custaram quase 30.000 vidas, afetando 206 milhões de pessoas e causando danos no valor de U\$ 366 bilhões, de acordo com o Escritório das Nações Unidas para a Redução de Riscos de Desastres (SELBY \& KAGAWA, 2012). 
A fim de efetivamente reduzir os riscos de desastres para as comunidades, o Fundo das Nações Unidas para a Infância (UNICEF) e das Nações Unidas para a Organização da Educação, Ciência e Cultura (UNESCO) reconhecem que a educação desempenha papel importante na redução da vulnerabilidade e na forma ação da resiliência. A educação pode ser um instrumento de construção do conhecimento, de habilidades e atitudes necessárias para se preparar e lidar com desastres, bem com o para ajuda os alunos e a com unidade a voltar a um a vida normal (SELBY \& KAGAWA, 2012).

Segundo um relatório elaborado pela UNESCO em 2005 denominado Década das Nações Unidas da educação para o desenvolvimento sustentável revela que os efeitos das ações educativas são extremamente positivos para a redução do risco de catástrofe.

\begin{abstract}
"As crianças que sabem como reagir no caso de terremoto, os líderes comunitários que aprenderam a avisar a sua comunidade a tempo de se protegerem dos riscos e camadas sociais inteiras que foram ensinadas a se preparar para enfrentar desastres naturais contribuem para melhorar as estratégias de atenuação dos efeitos dos desastres. Educação e saber forneceram à sociedade estratégias de autoajuda que diminuem sua vulnerabilidade e melhoram sua vida" (UNESCO, 2005).
\end{abstract}

No Relatório da UNICEF intitulado "Redução do Risco de Desastres nos Currículos Escolares: Estudos de Casos de Trinta Países" (UNICEF, 2012) é feito um mapeamento de países que estabelecem ações para a redução dos riscos de desastres no sistema educacional. Há estudos detalhados sobre as experiências nacionais, os desafios e benefícios de priorizar o tema na educação. Um dos estudos de caso diz respeito ao Peru, Chile e Colômbia que apresentam boas iniciativas difundidas nas matérias da educação primária ${ }^{1}$, focadas principalmente nas disciplinas de Geografia e História. No Peru por exemplo, existe uma organização não governamental de Prevenção e de Estudo de Desastres (PREDES) que elaborou um guia de metodologia para a incorporação da gestão de risco nas escolas. Este guia fornece diretrizes para todas as áreas curriculares da escola do nível primário e secundário. Porém o projeto-piloto não foi amplamente difundido nacionalmente (SELBY \& KAGAWA, 2012).

Os estudos nos países mostram que a abordagem mais frequente para redução de riscos de desastres é integrada numa faixa restrita de disciplinas como as ciências físicas e naturais, embora haja exemplos da sua presença numa vasta gama de matérias. $O$ desenvolvimento profissional de professores também precisa avançar. Em vários casos, os professores recebem um manual para ensinar assuntos referentes a Redução de Riscos de Desastres, porém sem treinamentos. Nos casos em que há alguma formação, no entanto, elas tendem a ser de curta duração em um evento único, sem um acompanhamento contínuo durante o processo de aprendizagem. Dessa forma, segundo o documento há uma necessidade de um desenvolvimento profissional mais sistematizado, pois nenhum exemplo de programas de formação inicial de professores foi encontrado (SELBY \& KAGAWA, 2012).

Autores como Afonso (2015; 2018), Afonso et. al (2019) e Armond \& Afonso (2011) destacam a importância da formação dos professores para a criação de estratégias capazes de trabalhar e reconhecer juntamente com seus alunos situações de riscos e de prevenção de desastres naturais. Para que os professores assumam esse papel é necessário que durante sua formação sejam estimulados e conscientizados sobre a importância do seu papel no ensino básico ao trabalharem com a inclusão e disseminação de temas acerca a prevenção de riscos, dinâmicas e da natureza, eventos extremos, entre outros. Afonso (2015, p. 193) reforça o papel de uma formação que estimule o contato com tais temáticas para que o professor se sinta capaz de trabalhar com esses conhecimentos em sala de aula: 
Para isso, é importante que ao longo de sua formação profissional, os licenciandos em Geografia possam ter contato com conceitos teóricos, métodos de investigação e análise dos elementos físico-naturais do espaço, associados aos subcampos científicos da Geografia Física e das Geociências (AFONSO, 2015).

\section{Marco de Sendai 2015-2030}

O Marco de Sendai foi apresentado no contexto da Terceira Conferência Mundial das Nações Unidas sobre a Redução do Risco de Desastres, realizada em março de 2015, em Sendai no Japão. A Conferência Mundial de Redução de Riscos de Desastres visava, entre outros objetivos, avaliar as ações cumpridas de acordo com Marco de ação de Hyogo no período de 2005-2015 para resiliência de comunidades e redução de riscos. Em resumo algumas das conclusões chegadas pela conferência foram a seguintes (UN, 2015, p. 10).

Mais de 700 mil pessoas perderam a vida, mais de 1,4 milhão de pessoas ficaram feridas e cerca de 23 milhões ficaram desabrigadas em consequência de desastres. No total, mais de 1,5 bilhões de pessoas foram afetadas por desastres de várias maneiras. Mulheres, crianças e pessoas em situação vulnerável foram afetadas desproporcionalmente. A perda econômica total foi de mais de US\$1,3 trilhões (UN, 2015).

Os números são claros ao demonstrar que mesmo com o acordo assinado em 2005 ocorreu pouca ou nenhuma mudança nas nações para a redução de risco, com os desastres atingindo cada vez mais um número maior de pessoas, principalmente os mais pobres. Ainda segundo UN (2015) a experiência aprendida com o Marco de Hyogo demonstra que muitas lacunas devem preenchidas como ser mais inclusivo com mulheres, crianças e jovens, pessoas com deficiência e idosos. Além disso, é necessário integrar setores públicos e privados, organizações da sociedade civil e instituições de pesquisa científica para colaborem em práticas de gestão do risco. $\mathrm{O}$ documento também expõe que devem ser intensificadas medidas de combate a degradação ao meio ambiente e a agentes causadores das mudanças climáticas, pois são fatores que agravam os riscos de desastres e consequências trágicas a toda população mundial.

Dessa forma, após a avaliação dos resultados do Marco Hyogo foi apresentado o Marco de Ação de Sendai estabelecido para o período de 2015 a 2030, sendo o Brasil um de seus signatários. $\mathrm{O}$ documento estabeleceu quatro ações prioritárias a serem cumpridas (UN, 2015, p. 14).

1. Compreender o risco de desastres;

2. Fortalecer a governança do risco de desastres para gerenciar o risco de desastres;

3. Investimento na redução do risco de desastres para a resiliência;

4. Aprimorar a preparação para desastres sendo capaz de gerar uma resposta eficaz e reconstruir de maneira eficiente e planejada (UN, 2015).

No contexto da educação a prioridade 1: Compreender o risco de desastres aborda quais práticas devem ser adotadas no contexto nacional e local (UN, 2015, p. 15).

Promover estratégias nacionais para fortalecer a educação pública e a conscientização sobre desastres redução de riscos, incluindo informações e conhecimentos sobre riscos de desastres, por meio de campanhas, mídias sociais e mobilização da comunidade, levando em consideração públicos específicos e seus necessidades (UN, 2015, p. 15). 
O documento deixa claro a importância do fortalecimento de estratégias visando a área educacional, pois é justamente a conscientização dos mais jovens que podem provocar mudanças e diminuição do paradigma atual das consequências de um desastre. Ter uma população consciente dos riscos e capaz de saber como agir diante deles é um passo importante para a resiliência da comunidade e para a queda no número de pessoas afetadas.

O Marco de Sendai também aborda a valorização da pesquisa científica e da comunidade acadêmica na integração de trabalhos voltados para metodologias de análise de risco, estudo e modelagem de cenários para compreensão de causas e consequências de desastres, contando com a colaboração da academia para o desenvolvimento de práticas de gestão de riscos locais e nacionais.

\section{A educação brasileira}

O cenário educacional brasileiro carece de muitos recursos, sejam eles humanos, estruturais ou financeiros. O ensino sobre os riscos dos desastres e como alcançar a resiliência ainda está engatinhando em sala de aula.

A educação resiliente estava amparada legalmente desde 2012 de acordo com a Política nacional de Proteção e Defesa Civil (Lei n $\left.{ }^{\circ} 2.608 / 2012\right)$ em seu artigo 29, alterou o artigo 26 da Lei de Diretrizes e Bases da Educação Nacional (Lei n 9.394/1996) expondo da seguinte forma:

$\S 7$ o Os currículos do ensino fundamental e médio devem incluir os princípios da proteção e defesa civil e a educação ambiental de forma integrada aos conteúdos obrigatórios (BRASIL. Lei $\mathrm{n}^{\circ} 9.394$ de 20 de dezembro de 1996).

Quadros (2017) ressalta que foi deixada uma lacuna entre o tema redução do risco de desastres e a educação, pois a lei não explica como deve ocorrer sua efetivação e quais são as práticas pedagógicas a serem abordadas em sala de aula. Portanto, não houve uma atuação efetiva do ministério da educação para cumpri-la e esclarecer como as escolas devem operar.

Contudo, para piorar, por meio da lei $\mathrm{n}^{\circ} 13.415$, de 16 de fevereiro de 2017 (BRASIL, 2017) que alterou importantes artigos da Lei de Diretrizes e Bases da Educação para estabelecer a nova Base Comum Curricular. Entre as alterações está justamente a mudança do artigo citado anteriormente, excluindo a obrigatoriedade dos princípios de proteção e defesa civil serem trabalhados no ensino básico e trazendo um novo artigo com aplicação bastante vaga com relação a educação ambiental e de prevenção dos riscos de desastres:

$\S 7^{\circ} \mathrm{A}$ integralização curricular poderá incluir, a critério dos sistemas de ensino, projetos e pesquisas envolvendo os temas transversais de que trata o caput (BRASIL, 2017).

A mudança do texto demonstra que a temática não é tratada com a devida importância pelo Governo Federal e diminui a conscientização da população acerca da prevenção. Afonso (2018) concorda que a alteração é preocupante, trazendo um grave retrocesso para a educação básica e, principalmente, tornando bastante perigoso o desconhecimento população sobre riscos provocados por eventos naturais extremos.

A nova Base Nacional Comum Curricular (BNCC) (BRASIL, 2018) traz em seu documento unidades temáticas para o ensino básico. Para a disciplina de Geografia cita- 
se a unidade temática "Natureza, ambiente e qualidade de vida" que trata exatamente das relações entre homem e natureza com temas como utilização dos recursos naturais, impactos ambientais, mudanças climáticas, degradação dos solos e recursos hídricos, entre outros temas. A unidade temática citada possibilita a introdução dos assuntos sobre desastres naturais, porém podendo ser apresentada de maneira superficial e distante de uma abordagem acerca prevenção de riscos.

Cita-se o caso da base curricular do Governo do Estado do Rio de Janeiro, em que na disciplina de Geografia a educação ambiental é tratada no sexto ano do ensino fundamental e no primeiro ano do ensino médio. A citação a seguir demonstra como o currículo apresenta a proposta para o primeiro ano do ensino médio de acordo a com Secretaria de Estado de Educação (SEEDUC).

\begin{abstract}
Analisar diferentes formas de ocupação ao confrontar os interesses socioculturais, políticos, ambientais e econômicos existentes na paisagem. Discutir criticamente o modelo de civilização baseado na exaustão dos recursos naturais. Contextualizar as principais conferências internacionais para o ambiente, seus princípios e propósitos. Identificar, comparar e analisar os principais problemas ambientais em diferentes escalas” (SEEDUC, 2012).
\end{abstract}

Analisa-se o currículo que trata especificamente da questão ambiental com seus problemas, impactos e discussões no mundo. Outros órgãos ligados ao gerenciamento de riscos e resiliência da população criaram projetos a serem implantados em escolas em locais com riscos em potencial. Desse modo, apresenta-se a seguir dois projetos analisados.

\title{
Centro Nacional de Monitoramento e Alerta de Desastres Naturais (CEMADEN)
}

O Centro Nacional de Monitoramento e Alerta de Desastres Naturais (Cemaden) criado em fevereiro de 2011 pelo Ministério da Ciência, Tecnologia e Inovação. A criação de um sistema de alerta que integrasse várias áreas do conhecimento, principalmente, de Meteorologia, Hidrologia, Geologia e Desastres Naturais foi fundamental para que o Governo Federal encerrasse com a ausência de um sistema capacitado para prevenir e mitigar danos (CEMADEN, 2018).

De acordo com o Anuário Brasileiro de Desastres Naturais de 2012, entre 1990 e 2012 foram registrados oficialmente 38.996 desastres em todo país, sendo $22 \%$ (8.515) ocorridos na década de 1990 e $56 \%$ (21.741) durante a década de 2000. Somente nos anos de 2010, 2011 e 2012 o total soma 22\% (8.740), ou seja, o número de casos em 3 anos é maior do que durante toda a década de 1990. A criação do centro de monitoramento ocorre justamente pelo país passar por grandes tragédias entre 2010 e 2012 (BRASIL, 2013).

O CEMADEN trabalha de acordo Plano Nacional de Gestão de Riscos e Resposta a Desastres elaborado a partir do diálogo conjunto entre os ministérios e os governos federal, estadual e municipal, coordenado pela Casa Civil. Para a atuação organizada das entidades, foram construídos os eixos que focaram a atuação governamental na prevenção contra os desastres naturais: mapeamento das áreas de risco, estruturação de sistema de monitoramento e alerta, obras estruturantes e, em médio prazo, o fortalecimento dos órgãos de defesa civil e apoio a um melhor planejamento urbano capaz de evitar a ocupação de áreas de risco (CEMADEN, 2018).

Infelizmente, mesmo com a criação da instituição o país ainda revive anualmente grandes tragédias. Pode-se justificar pelos grandes cortes de orçamento que a instituição sofreu. Desde o ano de 2013 até 2018 o orçamento do órgão caiu cerca de 85\%, 
acarretando no atraso de instalação de equipamentos importantes para previsão de inundações, além de prejudicar equipamentos já em operação devido à falta de verba para manutenção. No primeiro ano da atual gestão federal utilizou-se menos de um terço do orçamento previsto na prevenção de inundações, deslizamentos e outras obras relacionadas (Folha de São Paulo, 2018; 2020).

Especificamente na cidade do Rio de Janeiro os anos de 2018, 2019 e 2020 passaram pela mesma problemática. Em 15 de fevereiro de 2018, uma precipitação intensa atingiu a cidade. Foram registrados vários pontos de alagamento, problemas nos transportes públicos e vias ficaram engarrafadas (Jornal O Globo, Sistema Alerta Rio, 2018). No mês de abril de 2019 novamente a cidade enfrentou uma forte chuva 343.4 mm em 24 horas, de acordo com o Sistema Alerta Rio (2019). O município entrou em Estágio de Crise, tendo sido registradas 10 mortes (Jornal O Globo, Sistema Alerta Rio, 2019).

No dia 02 de fevereiro de 2020 a cidade passou por mais uma calamidade. A precipitação extrema ocasionou o decreto de Estágio de Atenção. Registraram-se de desabamentos, bolsões de água nas principais vias e acionamento das sirenes. O bairro de Realengo, localizado na Zona Oeste, foi um dos mais atingidos com deslizamentos e inundações (Jornal O Globo, Sistema Alerta Rio, 2020).

\section{CEMADEN Educação}

O Projeto Cemaden Educação criado em 2014 pelo Centro Nacional de Monitoramento e Alertas de Desastres Naturais e atua junto às escolas de Ensino Médio localizadas em municípios vulneráveis a desastres socioambientais (CEMADEN, 2018).

O projeto tem como objetivo contribuir para a geração de uma cultura da percepção de riscos de desastres, no amplo contexto da educação ambiental e da construção de sociedades sustentáveis e resilientes (CEMADEN, 2018).

Com a implantação nas escolas elas tornam-se uma sede local do CEMADEN, ou seja, um espaço para realizar pesquisas, monitorar o tempo e o clima, compartilhar conhecimentos, entender e emitir alertas de desastres. Além de fazer a gestão participativa de intervenções com suas comunidades. É importante ressaltar que mesmo com os cortes de verbas, citados anteriormente, o projeto não encerrou suas atividades e até o ano de 2020 está presente em mais de 110 escolas e instituições de ensino (CEMADEN, 2020).

Para o conhecimento mais aprofundado do projeto realizou-se um questionário via e-mail com a equipe responsável, sendo as respostas apresentadas a seguir. O questionário na íntegra encontra-se no apêndice deste artigo.

De acordo com a equipe qualquer escola do país pode fazer o cadastro gratuitamente no site do Cemaden Educação. A escolha da escola é feita com base em algumas preferências como estar localizada em um dos municípios monitorados pelo Cemaden e ter o ensino médio como um de seus segmentos.

A temática do projeto é "Educação para Redução de Riscos de Desastres", elaborada para alunos do Ensino Médio. Contudo, há abertura para alunos de outras faixas etárias. Umas das principais metas é que a temática seja adotada no Projeto-PolíticoPedagógico da escola. Com relações as atividades os profissionais do Cemaden sugerem atividades e períodos para atuação e dão liberdade para professores que avaliarem quais serão as mais propicias para serem trabalhadas, pois justamente são o que melhores conhecem seus alunos e a realidade local.

$\mathrm{Na}$ última questão é respondido que na maioria dos projetos os educadores não recebem uma capacitação específica para que haja uma continuação com turmas futuras. 
Segundo a equipe existe apenas capacitação em projetos específicos, por exemplo um Projeto de Extensão Universitária em Universidades públicas ou parcerias com Municípios ou Estado.

\section{Projeto Lorena Resiliente}

Em uma de suas atividades o Centro Nacional de Monitoramento e Alertas de Desastres Naturais atua na cidade de Lorena, interior do estado de São Paulo. De acordo com a Defesa Civil local o município apresenta principalmente riscos de alagamentos e enchentes nas áreas urbanas, dessa forma a Prefeitura decidiu investir e trabalhar conjuntamente com o Cemaden em estratégias para prevenção de desastres (PREFEITURA DE LORENA, 2016)

A parceria envolveu a instalação de pluviômetros, capacitação e pesquisa, trocas de experiências entre pesquisadores, professores, gestores municipais e Defesa Civil Municipal. O objetivo é a redução de riscos de desastres no município e promover ações para tornar a cidade mais resiliente (CEMADEN, 2016).

No primeiro encontro junto aos professores da rede municipal de Educação, o Cemaden fez apresentações sobre as atividades de monitoramento e alertas, riscos e vulnerabilidades naturais e socioambientais, além de atividades práticas em campo. Também tiveram exposições sobre o funcionamento dos pluviômetros semiautomáticos, do Projeto Pluviômetros Comunitários (CEMADEN, op. cit.).

O projeto ocorreu durante os anos letivos de 2016 e 2017 em escolas estaduais e municipais. Trabalhou-se principalmente com alunos do $6^{\circ}$ ano do Ensino Fundamental II. Entre atividades pedagógicas ocorreram abordagens de diversos temas como clima, desastres naturais, sustentabilidade, práticas e ações no meio ambiente, utilização do pluviômetro para acompanhamento das chuvas, dengue, entre outros. Entre as atividades práticas relativas a pesquisa e monitoramento, os alunos realizaram levantamento de riscos em áreas próximas das escolas e diagnosticaram a situação do Ribeirão Mandi, constatando problemas de assoreamento, lixo nas margens, falta de vegetação e levantamento de riscos em áreas próximas das escolas. As experiências sobre a formação da chuva, por meio da produção de vídeo, envolvendo as disciplinas de Ciências, História, Geografia, Arte e Matemática (CEMADEN, op. cit.).

\section{Defesa Civil do município do Rio de Janeiro}

A defesa civil é o conjunto de ações preventivas, de socorro, assistenciais e reconstrutivas destinadas a evitar ou minimizar os desastres naturais e os incidentes tecnológicos, preservar o moral da população e restabelecer a normalidade social (DEFESA CIVIL, 2016).

No Brasil, as primeiras ações e estratégias de proteção e segurança dirigidas à população começaram a ser tratadas em 1942, após o afundamento de navios militares e civis nos litorais de Sergipe e da Bahia. A notícia dos naufrágios e a morte de civis gerou com que a população brasileira fosse às ruas exigindo do governo uma resposta imediata aos ataques, que culminou com a declaração de guerra do Brasil contra a Alemanha e a Itália e a criação do Serviço de Defesa Passiva Antiaérea, em agosto de 1942 (DEFESA CIVIL, 2016).

Em 1943, a denominação de Defesa Passiva Antiaérea é alterada para Serviço de Defesa Civil, sob a supervisão da Diretoria Nacional do Serviço da Defesa Civil, do Ministério da Justiça e Negócios Interiores. Este órgão é extinto em 1946, bem como, 
suas Diretorias Regionais criadas nos Estados, Territórios e no Distrito Federal (DEFESA CIVIL, 2016).

O Brasil começou a se estruturar em função de fortes chuvas que assolaram a região Sudeste entre 1966 e 1967, provocando enchentes no Estado da Guanabara e deslizamentos na Serra das Araras/RJ e Caraguatatuba/SP. Devido a isso foi constituído um Grupo de Trabalho, no âmbito do Estado da Guanabara, com a finalidade de estudar a mobilização dos diversos órgãos estaduais em casos de catástrofes. Este grupo elaborou o Plano Diretor de Defesa Civil do Estado da Guanabara que criou as Coordenadorias Regionais de Defesa Civil - REDEC, definiu atribuições para cada órgão componente do Sistema Estadual de Defesa Civil e organizou a primeira Defesa Civil Estadual do Brasil (BRASIL, 2018).

Na cidade do Rio de Janeiro a Defesa Civil foi criada a partir de 1978, devido à necessidade da existência de um órgão que pudesse prevenir a ocorrência de desastres ou minimizar seus efeitos. Atualmente, mobiliza e orienta a população a adotar medidas preventivas e de resposta rápida diante de situações de riscos provocadas por fenômenos naturais, estando suas ações de acordo com Política Nacional de Proteção e Defesa Civil (BRASIL, Lei $\mathrm{n}^{\circ} 12.608 / 2012$ ), a mesma lei alterou a estrutura nacional defesa civil no Brasil ao criar subsecretarias em todos os estados e municípios do Brasil (DEFESA CIVIL, 2016).

\section{Projeto Defesa Civil nas Escolas}

O respectivo projeto trabalha com escolas, instituições de ensino e universidades tanto públicas como privadas na cidade do Rio de Janeiro. Contudo, tem como prioridade atuar no ensino básico, especificamente o $6^{\circ}$ ano do Ensino Fundamental II. Entre seus principais objetivos estão a conscientização sobre os tipos de riscos presentes na cidade e estimular a discussão do tema na comunidade incentivando a formação de uma cultura de prevenção (DEFESA CIVIL, 2016).

Para aprofundar os conhecimentos sobre mais esse projeto também foi realizada uma entrevista com Ivana Soares, Coordenadora do Centro de Treinamento da Subsecretaria de Defesa Civil - SUBDEC/CT, acerca do seu funcionamento e seu conteúdo será apresentada a seguir. O questionário na íntegra encontra-se no apêndice deste artigo.

Segundo a coordenação do projeto no ano de 2018 foi realizada uma reformulação no projeto. A escolha das escolas participantes a partir da reformulação pode ser sugerida pela própria Defesa Civil, antes quem julgava quais escolas participariam era apenas a Secretaria Municipal de Educação (DEFESA CIVIL, 2018).

Dentro da unidade escolar o projeto visa trabalhar temas como: Noções de Defesa Civil e prevenção de acidentes domésticos; Educação ambiental e desastres naturais com foco na cidade; Noções básicas de primeiros socorros. Ocorre a entrega de materiais didáticos como todos os conteúdos teóricos para professores e alunos para auxilio em sala de aula (Figura 1). 


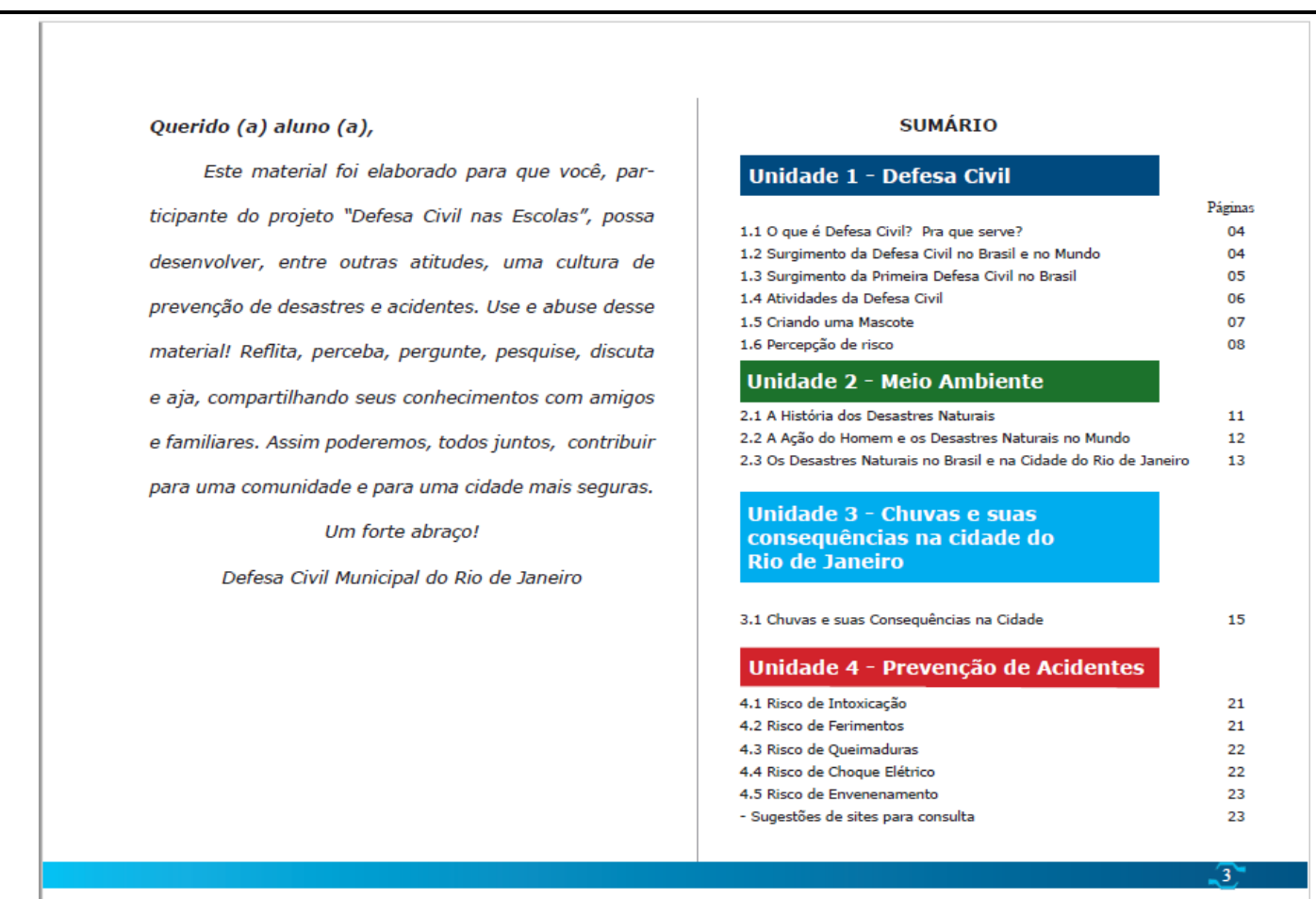

Figura 1: Sumário do material didático entregue aos alunos. Fonte: Caderno do Aluno - Defesa Civil, 2016

É proposto que professores trabalhem os temas através de aulas expositivas, projetos que integrem várias classes e momentos lúdicos. Ainda segundo a coordenação do projeto também é sugerido que a matéria seja tratada transversalmente ao currículo escolar facilitando a aplicação. Essa tratativa transversal faz com que a duração do projeto possa ocorrer durante todo ano letivo (DEFESA CIVIL, 2018).

Referente a capacitação dos educadores para a realização do trabalho na escola, foi comentado que na metodologia anterior havia um pequeno período de preparação com o professor para apresentar o projeto, esclarecer dúvidas e distribuição do livro do professor. A partir da nova proposta haverá a capacitação de multiplicadores da Secretária Municipal de Educação juntamente com as Coordenadorias Regionais de Educação (CRE's) para capacitar os professores na proposta do projeto.

O currículo elaborado abrangia o $5^{\circ}$ ano do Ensino Fundamental I. A partir de 2018 iniciou-se um trabalho experimental com o $6^{\circ}$ ano, presente no Ensino Fundamental II, e gradualmente planeja-se avançar para as séries seguintes nos próximos anos. Está havendo também a criação de um aplicativo que visa aproximar ainda mais os alunos ao tema por meio da tecnologia, já que grande parte dos alunos já possui um smartphone, e aumentar o alcance da comunicação (DEFESA CIVIL, 2018).

\section{Considerações Finais}

A pesquisa mostrou como projetos visando uma educação preventiva e com objetivos de tornar as pessoas desde jovens conscientes dos riscos e preparadas para agir são importantes para que a população seja atuante de acordo com sua realidade e não apenas passiva diante da demora do poder público em criar outros mecanismos preventivos.

Ainda há muito a ser feito nesse sentindo, pois, mesmo estando amparado legalmente o tema da redução de riscos de desastres é totalmente ignorado no âmbito educacional, seja nos livros didáticos distribuídos na rede pública, seja pelos próprios docentes que mostram desconhecimento sobre a obrigatoriedade de abordarem o assunto 
e desconhecimento sobre o próprio assunto, deixando de lado o tema de suma importância.

O artigo demonstrou que mesmo o Brasil sendo signatário do Marco de Sendai ainda não realizou as ações prioritárias para a área da educação, podendo trazer como resultados uma demora maior na mudança do cenário dos desastres do país. Infelizmente, a realidade de tragédias ainda continuará acontecendo enquanto a prevenção for pouco eficiente e valorizada tanto pelos governantes quanto pela população.

\section{Nota}

1 - Para saber mais acesse: https://novaescola.org.br/conteudo/8745/para-aprender-com-nossos-vizinhos

\section{Referências bibliográficas}

AFONSO, A. E. Perspectivas e possibilidades do ensino e da aprendizagem em Geografia Física na Formação de Professores de Geografia. Tese de Doutorado (Área de Concentração: Planejamento e Gestão Ambiental) - Universidade Federal do Rio de Janeiro, Instituto de Geociências, Departamento de Geografia, Programa de Pós-Graduação em Geografia, Rio de Janeiro, 2015.

AFONSO, A. E. Contribuições da Geografia Física para o ensino e aprendizagem geográfica na educação básica. Revista Educação Geográfica em Foco, [S.1.], v. 1, n. 2, dec. 2018. ISSN 2526-6276. Disponível em: $<$ http://periodicos.pucrio.br/index.php/revistaeducacaogeograficaemfoco/article/view/812>.

Acesso em: 13. mai. 2020

AFONSO, A. E.; SILVA, L. F. H. S.; COSTA, D. G. Formação de professores e educação geográfica: trabalho de campo autônomo com vistas à identificação de riscos geomorfológicos. Geosaberes, Fortaleza, v. 10, n. 22, p. 26 - 35, set. 2019. ISSN 2178-0463.

Disponível em: 〈http://www.geosaberes.ufc.br/geosaberes/article/view/816>.

Acesso em: 14 mai. 2020

AMARAL, R.; TOMINAGA, L. K; SANTORO, J. Desastres naturais: conhecer para prevenir. Instituto Geológico. São Paulo, 2009.

ARMOND, N.B. AFONSO, A.E. A Geografia Física contemporânea no Brasil, a formação de professores e os esforços de integração: debates sobre os sentidos e propósitos do conhecimento. In: XI Encontro Nacional de Práticas de Ensino de Geografia, v. 1. p. 1-10, Goiânia (GO). 2011.

BRASIL. Ministério da Educação; Secretaria de Educação Básica; Secretaria de Educação Básica. Conselho Nacional de Educação. Base Nacional Comum Curricular. Brasília, 2018. Disponível em: http://basenacionalcomum.mec.gov.br/. Acesso em: 16 mai. 2020

BRASIL. Lei n ${ }^{\circ}$ 9.394, de 20 de dezembro de 1996.

Disponível em: http://www.planalto.gov.br/CCIVIL_03/LEIS/L9394.htm

Acesso em: 13 mai. 2020

BRASIL. Ministério da Integração Nacional. Secretaria Nacional de Defesa Civil. Histórico da Defesa Civil.

Disponível em: http://www.mi.gov.br/defesa-civil/apresentacao/293-secretaria-nacional-de-protecao-edefesa-civil/5950-historico-da-defesa-civil

Acesso em: 15 fev. 2018.

BRASIL. Política Nacional de Proteção e Defesa Civil. Lei no 12.608, de 10 de abril de 2012.

Disponível em:

http://www.planalto.gov.br/ccivil_03/_Ato2011-2014/2012/Lei/L12608.htm

Acesso em: 13 mai. 2020 
BRASIL. Lei $\mathbf{n}^{\mathbf{0}}$ 13.415, de 16 de fevereiro de 2017.

Disponível em:

https://www.planalto.gov.br/ccivil_03/_ato2015-2018/2017/lei/113415.htm

Acesso em: 13 mai. 2020

CENTRO NACIONAL DE MONITORAMENTO E ALERTA DE DESASTRES NATURAIS (CEMADEN). MINISTÉRIO DA CIÊNCIA, TECNOLOGIA, INOVAÇÕES, COMUNICAÇÕES.

Disponível em: https://www.CEMADEN.gov.br/CEMADEN-educacao/

Acesso em: 20. jun. 2018

CEMADEN EDUCAÇÃO. MINISTÉRIO DA CIÊNCIA, TECNOLOGIA, INOVAÇÕES, COMUNICAÇÕES. 2019

Disponível em: http://educacao.cemaden.gov.br/aprenderparaprevenir2019

Acesso em: 16 mai. 2020

DEFESA CIVIL DO MUNICÍPIO DO RIO DE JANEIRO.

Disponível em: http://www.rio.rj.gov.br/web/defesacivil

Acesso em: 22. jun. 2018

DEFESA CIVIL DO MUNICÍPIO DO RIO DE JANEIRO. Projeto Defesa Civil nas escolas. Caderno didático. Rio de Janeiro, 2016

Disponível em: http://www.rio.rj.gov.br/web/defesacivil/projeto-defesa-civil-nas-escolas

FUNDO DAS NAÇÕES UNIDAS PARA A INFÂNCIA (UNICEF). Redução do risco de Desastres nos Currículos escolares. Genebra, Suíça, 2012.

JORNAL O GLOBO. 15 de fevereiro de 2018.

Disponível em: https://g1.globo.com/rj/rio-de-janeiro/noticia/chuva-leva-rio-de-janeiro-a-entrar-emestagio-de-crise.ghtml

Acesso em: 15 mai. 2020

JORNAL O GLOBO. 08 de abril de 2019.

Disponível em: https://g1.globo.com/rj/rio-de-janeiro/noticia/2019/04/08/tempo-muda-no-rio-comprevisao-de-chuva-raios-e-ventos.ghtml

Acesso em: 15 mai. 2020

JORNAL O GLOBO. 02 de fevereiro de 2020.

Disponível em:

https://g1.globo.com/rj/rio-de-janeiro/noticia/2020/02/02/rio-tem-chuva-na-noite-de-domingo-e-entra-emestagio-de-mobilizacao.ghtml

Acesso em: 16 mai. 2020

JORNAL FOLHA DE SÃO PAULO. Edição de 02 de março de 2018.

Disponível em:

http://temas.folha.uol.com.br/natureza-do-desastre/introducao/sem-verbas-centro-federal-tem-

equipamentos-de-r-14-milhoes-parados.shtml

Acesso em: 15 mai. 2020

JORNAL FOLHA DE SÃO PAULO. Edição de 29 de janeiro de 2020.

Disponível em: https://www1.folha.uol.com.br/cotidiano/2020/01/gasto-do-governo-com-prevencao-dedesastres-e-o-menor-em-11-anos.shtml

Acesso em: 15 mai. 2020

ORGANIZAÇÃO DAS NAÇÕES UNIDAS PARA A EDUCAÇÃO, A CIÊNCIA E A CULTURA (UNESCO). Década da Educação das Nações Unidas para um Desenvolvimento Sustentável, 2005-2014. Brasília, 2005.

PREFEITURA DE LORENA. Projeto Lorena Resiliente 2016. 
Disponível em: http://www.lorena.sp.gov.br/wordpress/index.php/2016/11/07/lorena-resiliente-educarpara-prevenir/

Acesso em: 03 fev. 2018

QUADROS, E. L. L. Redução do risco de desastres aplicado à educação em ciências: representações de risco de alagamento por alunos de Geografia. Programa de Pós-Graduação, Pontifícia Universidade Católica. Porto Alegre, 2017.

ROSMAN, P. C. C.; AZEVEDO, J.P. S.; NOBRE, C.; LUIGI, G.; D’ORSI, R.; SOARES, M. L. G. Relatório Região Metropolitana do Rio de janeiro: vulnerabilidades e mudanças climáticas. Escola Politécnica - UFRJ, 2012.

SISTEMA ALERTA RIO. FUNDAÇÃO GEO-RIO.

Disponível em: http://alertario.rio.rj.gov.br/maiores-chuvas/

Acesso em: 15 mai. 2020

SECRETARIA DE ESTADO DE EDUCAÇÃO (SEEDUC). Currículo Mínimo: Geografia. Rio de Janeiro, 2012.

SELBY, D.; KAGAWA, F. Redução do Risco de Desastres no Currículo Escolar: Estudos de Casos de Trinta Países. UNESCO/UNICEF, Genebra, Suíça, 2012.

UNITED NATIONS (UN). Sendai Framework for Disaster Risk Reduction 2015-2030. Third United Nations World Conference on DisasterRisk Reduction. Sendai, Japan, 2015.

\section{Apêndice}

Questionário realizado com o Centro Nacional de Monitoramento e Alertas de Desastres naturais (CEMADEN).

Caro André Luiz,

É com satisfação que recebemos sua mensagem e respondemos suas indagações.

Aproveitamos também para perguntar sobre a temática do seu trabalho e como entrará o projeto Cemaden Educação na sua pesquisa.

Em relação às suas questões:

1) Como é feita as escolhas dos locais e das escolas?

Todas as escolas podem se inscrever no projeto, de forma voluntária e gratuita, por meio do site oficial http://educacao.cemaden.gov.br/

Damos preferência as escolas localizadas nos municípios monitorados pelo Cemaden http://www.cemaden.gov.br/municipios-monitorados/ que atuam com Ensino Médio, no entanto todas as escolas são bem-vindas a trabalhar com a temática da "Educação para Redução de Riscos de Desastres" e se cadastrar no projeto.

2) Como é definido o tempo de projeto no local e como é definido qual atividade será realizada? (ex: cartografia social)

Não há um tempo específico. A ideia é que as escolas localizadas em áreas de riscos adotem essa temática no seu Projeto Político Pedagógica. São os professores que escolhem as atividades para desenvolver junto aos estudantes. Em cada atividade disponível no site há sugestão de tempo estimado e periodicidade.

3)Existe capacitação para os educadores das escolas para garantia de continuação do projeto? 
Por enquanto, a capacitação só ocorre quando há um projeto específico, por exemplo: Projeto de Extensão Universitária da UNESP, UFF (etc) ou parcerias com Municípios ou Estado.

4) O trabalho é feito apenas com ensino médio?

O projeto foi elaborado para o Ensino Médio. As atividades disponíveis no site são direcionadas para esse público. Contudo, há abertura para as escolas envolverem outras faixas etárias.

Para obter mais informações consulte os seguintes materiais:

- Site oficial http://educacao.cemaden.gov.br/site/project/;

- Livro:Redução de Vulnerabilidade a Desastres: do conhecimento à ação

Capítulo 24. A escola e a comunidade: ciência cidadã e tecnologias digitais na prevenção de desastres

https://preventionroutes.weebly.com/capiacutetuloschapters.html

\section{Questionário realizado com Ivana Soares, Coordenadora do Centro de Treinamento da Subsecretaria de Defesa Civil - SUBDEC/CT}

1) Como é feita as escolhas dos locais e das escolas?

2) Como é definido o tempo de projeto no local?

3) Existe capacitação para os educadores da escolas para garantia de continuação do projeto após a saída dos instrutores?

4) O trabalho é feito com quais segmentos de ensino? (ex: ensino fundamental, ensino médio)

Bom dia André,

O Projeto Defesa Civil nas Escolas está passando por uma reformulação em sua metodologia. Vou responder as suas questões nas duas versões.

1) Anteriormente não tínhamos nenhum envolvimento na escolha das Escolas Municipais. A indicação acontecia no âmbito da SME e nunca soubemos como se dava a escolha. Na nova proposta a Defesa Civil já pode sugerir;

2) Por ser um tema transversal, o projeto pode ser tratado durante todo o ano pelo Professor, com abordagens nas diversas disciplinas;

3)Na proposta anterior, a Defesa Civil tinha um momento com o Professor, onde o projeto era apresentado e tirávamos dúvidas, bem como, criamos um link com diversos materiais para apoio e era distribuído um livro do professor. Nessa nova concepção, vamos capacitar multiplicadores da SME (eles são profissionais das CRE's que já foram selecionados pela Secretaria para tal) e esses profissionais capacitarão os professores e estamos construindo um aplicativo, também, que será mais uma ferramenta tanto para $\mathrm{o}$ professor quanto para o aluno;

4) Até o ano passado, trabalhávamos com o $5^{\circ}$ ano, ou seja, o último ano do Ensino Fundamental I. Na nova proposta, iniciaremos o trabalho com o $6^{\circ}$ ano "experimental", que é o primeiro ano do Ensino Fundamental II. É chamado de experimental, pois ao invés de ter vários professores, segue a mesma linha do ensino fundamental I, onde o professor é generalista. Esse modelo já está inserido em $70 \%$ das escolas da rede pública do Município do Rio de Janeiro. Mas pretendemos avançar para outras séries, nos próximos anos.

Espero ter elucidado suas dúvidas e caso queira qualquer outra informação, estamos à disposição. 